\title{
Exploring Construction of College English Writing Course from the Perspective of Output-Driven Hypothesis
}

\author{
Zhang Ying ${ }^{1}$ \\ ${ }^{1}$ English Department, North China Electric Power University, Baoding, Hebei Province, China \\ Correspondence: Zhang Ying, English Department, North China Electric Power University, Baoding, Hebei \\ Province, China.
}

\author{
Received: October 29, 2017 Accepted: January 22, 2018 Online Published: January 24, 2018 \\ doi: 10.5539/elt.v11n2p188 URL: http://doi.org/10.5539/elt.v11n2p188
}

\begin{abstract}
English writing is regarded as the most difficult task by Chinese EFL learners. Due to the existing problems in present college English writing instruction, teachers fail to provide effective guidance in students' writing process and students report a low level of motivation and confidence in writing tasks. Through purposeful reading discussions driven by writing tasks, students are provided with sufficient opportunities to receive language input. Reading-to-writing activities, based on output-driven hypothesis, help students consolidate and internalize linguistic and stylistic knowledge acquired in reading. This study mainly focuses on integrated reading-to-writing mode applied in teaching college English writing based on output-driven hypothesis, aiming at helping teachers guide students to improve their language proficiency so as to enhance the efficiency of writing.
\end{abstract}

Keywords: writing instruction, integrated reading and writing, output-driven hypothesis

\section{Introduction}

English writing ability is one of the fundamental parts of one's English competence, but also plays a significant role in communication. For Chinese College EFL learners, writing is regarded as the most difficult task among the five tasks of listening, speaking, reading, writing and translating either because they don't have any ideas to write about or because they don't know how to express their ideas in English. As a result, they often feel frustrated by writing tasks and gradually lose interest in writing in English. Teachers also find it confusing teaching writing because of students' poor performance in writing course. Despite the fact that both teachers and students devote a lot of time and effort, students still fail to make any obvious improvement in their writing abilities. Teachers usually complain about the large number of mistakes made by students in writing assignments, including poor language, unclear ideas, lack of logic connections between different paragraphs. On one hand, students feel an urgent need to improve their writing abilities quickly and efficiently. On the other hand, the current teaching and learning activities in college English curriculum lead to the imbalanced development of students' writing abilities. In-class teaching attaches more importance to students' development of reading and listening abilities, the input of language, but students' development of writing and speaking abilities, the output of language, are greatly inadequate. Teachers normally pay more attention to giving feedback on students' final writing results but not the writing process. Consequently, this teaching model directly leads to the lack of sufficient instruction and guidance in students' writing process. Writing plays an important role in EFL learning process, so how to promote students' development of productive ability of writing through effective use of input has become an increasingly important issue for many language teachers and researchers.

\section{Literature Review}

\subsection{Input Hypothesis}

The relationship between input and output in second language acquisition is an important area of research for both linguists and language teachers. Krashen (1985) puts forward the theory of comprehensible input " $i+1$ " to emphasize the role of input in the process of second language acquisition. " $i$ " represents the language learner's present proficiency level, and " +1 " refers to the level of language just slightly higher than the learner's present level. Krashen (1985) claims that humans acquire language in only one way, that is, by understanding messages or by receiving comprehensible input. Therefore, comprehensible input is an important condition for language 
acquisition, and high receptive skills will naturally results in high productive skills. According to Krashen, input is the only resource of acquiring language, and the output of language, which has no direct effect on learners' second language development, is only a symbol and not a necessary condition for second language acquisition.

\subsection{Output Hypothesis}

Swain (1995) argues that comprehensible input is an important prerequisite for acquiring second language, but it is inadequate for a fluent process of SLA. Instead, learners must have sufficient opportunities to use and practice the language acquired on the basis of comprehensible input, so that they can reach fluency, similar to the level of native speakers. The production process of language is a fundamental part of language acquisition. Swain (1995) holds that one of the key reasons for the fact that students make a lot of grammatical errors is that they rarely have opportunities to practice the language.The output of language is necessary and significant in the process of SLA, for it can improve the accuracy and proficiency of second language learners' expressions in three aspects. First, output of language can raise learners' awareness of their linguistic difficulties in second language development. Second, output facilitates learners' hypothesis-testing. With opportunities provided in the production process, learners can try out their new structures in the target language to improve their knowledge of how to modify their language in use. Third, output has a metalinguistic function in SLA. In production of language, learners can reflect upon their own target language use, which promotes their process of understanding, controlling and internalizing of the linguistic knowledge. Swain (1995) asserts that only being pushed, production can assist language acquisition.

\subsection{Output-driven Hypothesis}

On the basis of Swain's (1995) output hypothesis, Wen Qiufang (2008) put forward output-driven hypothesis. It is claimed that output is both a goal of learning a foreign language and a means to promote deep understandings of input. The hypothesis contains three sub-assumptions: 1) output has greater driving force in learners' development of foreign language abilities than input. A learning process that does not have an output-driven learning process, even if there is a high-quality input, is limited and inefficient; 2) it is more significant to develop students' productive skills of speaking, writing and translating than to cultivate their receptive skills of reading and listening in terms of social functions of using a foreign language; 3) output-oriented integrated teaching method is more effective than training of individual skills and better to meet the needs of students in the future employment. According to Wen (2008), unlike in traditional English classes, listening or reading tasks are not just about the training of listening or reading abilities, but more importantly, listening and reading are to improve students' enthusiasm to use the language in oral or written communication. Output-driven hypothesis provides a powerful theoretical support for the research of EFL teaching in China. The implications for EFL teaching is that input and output are interdependent in the development of learners' foreign language competence. Only with input, learners fail to produce the target language in a fluent and accurate way. Linguistic production tasks enable learners to use and internalize the input materials efficiently to improve the quality of output.

\subsection{The Connection between Reading and Writing}

In EFL teaching, reading and writing activities are interrelated. If there is no writing output as a driving force, learners' interest, efficiency and persistence in reading will be greatly affected, which eventually lowers the quality of their writing. Grabe (2001) points out that writing can be improved through extensive reading. Taylor \& Beach (1985) argue that writing integrated with reading can bring great benefits to writing instruction. Integrating reading and writing can improve learners' writing skills and fluency (Kern\&Schultz, 1992; Sasaki, 2004). Accordingly, before writing, learners should be provided with enough opportunities to receive language input through purposeful reading and the reading materials should be selective based on specific writing tasks. In the process of writing, learners can consolidate their existing knowledge of vocabulary, grammar, syntax and pragmatic use acquired in reading. In the light of the given research, this study is to explore and discuss an effective mode of teaching writing by combining reading activities in EFL writing instruction.

\section{Construction of Teaching Mode of English Writing Course from the Perspective of Output-driven Hypothesis}

\subsection{Pre-writing Reading}

Integrating reading and writing activities in the teaching mode of English writing course requires that the reading materials should be selected according to the needs of output writing tasks. According to particular writing topics and writing tasks, the reading materials that are consistent with the theme, style and writing skills of the writing tasks are used for deep reading. The output-driven reading tasks enable students to have a stronger motivation and more specific purpose of conducting reading. In addition, the teaching of reading before writing is not a 
simple decoding process of the text or the teaching of reading skills, but a process of analyzing practical writing skills, collecting a wide range of writing materials, accumulating rich language knowledge, enhancing students' comprehensive language ability and cultivating their creative thinking. In other words, reading provides examples for writing. Wang (2012) claims that writing tasks combining with reading activities enable learners to use what are learned immediately. With the guidance of teachers, students can get explicit knowledge of writing from reading materials and then apply them to writing. Accordingly, students feel more confident in the latter writing task.

\subsection{While-reading Discussion}

Analysis of data and the reporting of the results of those analyses are fundamental aspects of the conduct of research. Accurate, unbiased, complete, and insightful reporting of the analytic treatment of data (be it quantitative or qualitative) must be a component of all research reports. Researchers in the field of psychology use numerous approaches to the analysis of data, and no one approach is uniformly preferred as long as the method is appropriate to the research questions being asked and the nature of the data collected. The methods used must support their analytic burdens, including robustness to violations of the assumptions that underlie them, and they must provide clear, unequivocal insights into the data.

\subsubsection{Content}

Students are guided to understand styles and features of different types of writing through the analysis of the text, such as, "three elements" (time, place, character) and "plot" (the beginning, development, climax, end) in narratives, description of "order" (chronological, spatial) in description, "definition" and "process explanation" in exposition, "contention" "reasoning" and "proof" in argumentation. Additionally, through asking questions purposefully, teachers direct students' attention to the topic content of reading materials. For example, what is the main idea of the reading passage? What is the topic sentence of each paragraph? With teachers' explicit instruction and interpretation, students are expected to acquire how to write topic sentence in each paragraph and how to convey the main points of an article to readers.

\subsubsection{Cohesion and Coherence}

Through discussions of reading materials, students get a better understanding of the logic in a well-organized passage. To convey ideas to readers in a clear and fluent way, the writer needs to employ cohesive devices to express a coherent meaning. In analyzing the organization of reading passages, teachers should highlight the important role of using cohesive devices or discourse markers, such as reference, substitution, ellipsis, conjunction, reiterations, collocations and other lexical means. This is an effective way for students to learn gradually how to employ cohesive resources and sentence structures and how to organize their ideas in writing with coherence and logic.

\subsubsection{Language Competence}

Students often feel frustrated in writing and they don't know how to use English words and sentences to express ideas. This is greatly due to their low proficiency level and limited vocabulary. A piece of good writing requires appropriate choice of words, accurate use of complex grammar and elegant expressions, so language plays an indispensable place in writing. While accumulation of language knowledge is an important target of EFL reading, through discussions of language use in reading passages, students are exposed to idiomatic expressions consciously and learn to use words and phrases appropriately in specific contexts. Therefore, students enhance their proficiency of language use and gradually internalize these expressions and structures in their mind. For example, in reading narratives, students are directed to how to make use of sensory words and rhetorical tools to create vivid pictures that readers can visualize in the story.

As is discussed, under teachers' guidance, students are provided with the knowledge about what content should be included in the beginning paragraph, the body paragraphs and the concluding paragraph in the process of reading. Besides, students get to acquire the skills of organizing their writing logically and expressing ideas in a fluent and coherent way. And students have a lot of opportunities to refine their written languages through imitation by using graceful expressions and complex grammatical rules. Therefore, output-driven reading tasks provide a number of interesting materials and opportunities for communication, imagination and creation, which makes students possess a stronger motivation and be fully prepared for the following writing tasks.

\subsection{In-class Writing}

Throughout the whole teaching process, writing, as the output form of language, is the most important part. It is also the primary goal of teaching to improve students' writing abilities. In the light of the purposeful analysis, in-depth discussion and appreciation of the input reading materials, students obtain adequate support from 
stylistic structure, topic content and linguistic device to write their first draft. The design of different writing tasks, based on actual teaching situations, should give full play to the input role of reading. For example, the writing tasks of sentence imitation and topic sentence expansion could be assigned as a basic form of practice for the less proficient students. Considering the connection between reading material and the writing task in the overall structure, teachers may ask students to practice continued writing and imitative writing. Focusing on the topics covered in the reading materials and in-class discussions, students may be required to accomplish a new writing task of a relevant topic or to rewrite the article from a different point of view. It's better for teachers to leave enough time to students to accomplish their first writing within the class time to ensure the efficiency and quality of their writing. And the combining of discussion and writing also cultivates students' critical thinking ability and logical thinking ability.

\subsection{Writing Assessment}

After students complete their writing tasks, both peer review and teacher review are conducted. First, students are guided to conduct peer review in small groups. Urzua (1987) points out that peer review enables students to be more reader-focused and perceive readers needs. Berg (1999) also believes that peer feedback can foster students' abilities to think critically and improve their writing qualities. In order to confirm the validity of peer review, the teacher should make relevant review rules in advance to guide the students to give peer feedback. A list of standards of writing should be offered. For example, from the overall structure and framework, is the writing article clear and reasonable? Is there a topic sentence? On the level of discourse, is the context cohesive and coherent? Are there any cohesive devices used in the context? Whether the use of cohesive devices is proper to have an integrity of a context? On language use, are the words appropriate and effective? Then each group is required to give a detailed feedback or comment on every group member's article and the assessment records are written. Peer review and feedback encourage students to develop a comprehensive understanding of content, structure and language of English writing. Through group discussions, students cultivate their abilities of discovering, analyzing and solving problems, which greatly helps promote their development of critical thinking abilities and autonomous learning abilities.

In the latter teacher review, teachers first get reflection upon the effectiveness of teaching and learning activities in class through students' mutual evaluation. For large classes, teachers can select the typical works from students in each writing task to give in-class review, such as providing excellent piece to highlight the positive aspects in writing, giving guidance and suggestions to the inadequacy in writing. After the assessment, students are required not only to revise their in-class writing to correct the errors and refine their expressions, but also to improve their structural organization and add more details to further develop the content.

\subsection{After-class Reading}

As discussed, reading English is an important way for students to acquire vocabulary, sentence patterns and discourse structure. Reading provides rich resources for writing in which students get rich authentic input and cultivate their thinking abilities. But due to the limited in-class time, students should take active part in after-class reading activities. First, considering students' different proficiency levels, teachers need to be selective and careful in recommending reading materials which should be in a moderate difficulty level to ensure the effectiveness of input. Second, teachers are expected to provide enough guidance to students in conducting extracurricular reading activities. For example, teachers should direct students' attention to different styles of writing so that students can focus on stylistic features and distinct language features. In addition, writing is not a simple list of isolated sentences, but the author's purposeful organization of contextually-linked discourse, thus students should be able to make use of outline, mind mapping and other tools to analyze the structure of the reading material, which gives them implications in how to make use of framework to organize ideas in a clear and logical way. And teachers should require students to takes notes in reading to accumulate useful words and expressions that promote the development of their mental lexicon.

\section{Conclusion}

In class, with the driving force of writing tasks, reading activities are conducted with specific purposes. Through reading analysis, students get prepared for the writing stage in terms of topic content, stylistic structure and linguistic resource. Meanwhile, the integration of reading and the writing activities raises students' awareness of the close connection between input and output, and students have a clear understanding that the input is the basis of the output and reading is indispensable in the writing process. Besides, a joint process of reading and writing, based on the output-driven hypothesis, greatly enhances students' interests and confidence in English writing. In this process, teachers should give sufficient guidance and help to motivate students to receive comprehensible input and maintain enthusiasm for class participation and extracurricular practice. In the following after-writing 
stage, peer review and teacher evaluation are effective means for students to revise their writing and to improve their writing strategies. Admittedly, the cultivation of writing abilities is a slow process, requiring the improvement of students' comprehensive language competence. Further long-term action research needs to be done to enhance the effectiveness of the present model by collecting empirical data in teaching practice.

\section{Acknowledgments}

This research was financially supported by "the Fundamental Research Funds for the Central Universities+2015MS68".

\section{References}

Berg, E. C. (1999). The effects of trained peer response on ESL students' revision types and writing quality. Journal of Second Language Writing, 8(3), 215-241. https://doi.org/10.1016/S1060-3743(99)80115-5

Grabe, W. (2001). Reading-Writing Relations: Theoretical perspectives and instructional practices. In D. A. H. Belcher (Eds.), Linking Literacies: Perspectives on L2 Reading-Writing Connections (pp. 15-39). Ann Arbor: The University of Michigan Press.

Kern, R. G., \& Schultz. J. M. (1992). The effects of composition instruction on intermediate level French students' writing performance: Some preliminary findings. Modern Language, 76, 1-13. https://doi.org/10.1111/j.1540-4781.1992.tb02572.x

Krashen S D. (1985). The Input Hypothesis: Issues and Implications. New York: Longman.

Sasaki. (2004). A multiple-data analysis of the 3.5 year development of EFL student writers. Modern Language Journal, 78, 178-189. https://doi.org/10.1111/j.0023-8333.2004.00264.x

Swain, M. (1995). Three functions of output in second language learning. In G. Cook, \& B. Seidlhofer (Eds.), Principles and practice in applied linguistics (pp. 25-44). Shanghai: Shanghai Foreign Language Education Press.

Taylor, B., \& Beach, R. W. (1985). The effects of text structure instruction on middle-grade students' comprehension and production of expository text. Reading Research Quarterly, 19(2), 134-146. https://doi.org/10.2307/747358

Urzua, C. (1987). You stopped too soon: Second language children composing and revising. TESOL Quarterly, 21, 279-304. https://doi.org/10.2307/3586736

Wang, C. M. (2015). Why does the continuation task facilitate L2 learning? Foreign Language Teaching and Research, 47(5), 753-762.

Wen, Q. F. (2008). On the output-driven hypothesis and reform of English-skill courses for English majors. Foreign Language World, 2, 2-9.

\section{Copyrights}

Copyright for this article is retained by the author(s), with first publication rights granted to the journal.

This is an open-access article distributed under the terms and conditions of the Creative Commons Attribution license (http://creativecommons.org/licenses/by/4.0/). 